\title{
Certification in cardiothoracic surgical critical care: A distinction for some or for all?
}

\author{
Nicholas D. Andersen, MD
}

\footnotetext{
From the Division of Cardiovascular and Thoracic Surgery, Department of Surgery, Duke University Medical Center, Durham, NC.

Disclosures: Author has nothing to disclose with regard to commercial support.

Received for publication Feb 8, 2016; accepted for publication Feb 10, 2016; available ahead of print March 12 , 2016.

Address for reprints: Nicholas D. Andersen, MD, Division of Cardiovascular and Thoracic Surgery, Duke University Medical Center, Box 3443, Durham, NC 27710 (E-mail: Nicholas.andersen@ duke.edu).

J Thorac Cardiovasc Surg 2016;152:37-8

$0022-5223 / \$ 36.00$

Copyright (c) 2016 by The American Association for Thoracic Surgery

http://dx.doi.org/10.1016/j.jtcvs.2016.02.022
}

Are all board-certified cardiothoracic surgeons qualified to provide cardiothoracic surgical critical care (CTSCC) services, or should this distinction be reserved for a subgroup of surgeons with advanced specialty certification (Figure 1)? Are there other strategic benefits to the creation of CTSCC certification pathways that should be considered by our leadership? In an expert opinion published in this issue of the Journal, Dr Sherif eloquently advocates for the development of a CTSCC subspecialty certificate from the American Board of Thoracic Surgery (ABTS), to recognize and support the unique field of practice that represents contemporary CTSCC medicine, and he provides a core competency framework. ${ }^{1}$ Notably, similar sentiments have been expressed by Dr Nevin Katz, President and Executive Director of the Foundation for the Advancement of Cardiothoracic Surgical Care, ${ }^{2,3}$ prompting significant attention from the ABTS.

The ABTS asserts that CTSCC is a core component of thoracic surgical training and examination that is already encompassed by existing ABTS certification. ${ }^{4}$ However, Dr Sherif and others contend that cardiothoracic surgeons risk being increasingly marginalized and isolated from the cardiothoracic intensive care unit (CTICU) by hospital administrators in favor of nonsurgeon specialists who hold discrete certifications in critical care medicine from other medical boards. Development of a comparable critical care certificate from the ABTS would be intended to counter this trend and reassert cardiothoracic surgeons' claim to primary responsibility over the care of CTICU patients, and elevate cardiothoracic surgeons to their rightful positions in leadership roles within the multidisciplinary CTICU hierarchy. In addition, the enhanced critical care skill set and increased involvement of cardiothoracic surgeons in CTICU care is predicted to improve the outcomes of our patients. These compelling justifications appear sufficient to move forward with the development of subspecialty CTSCC certification pathways, yet some important challenges warrant consideration.

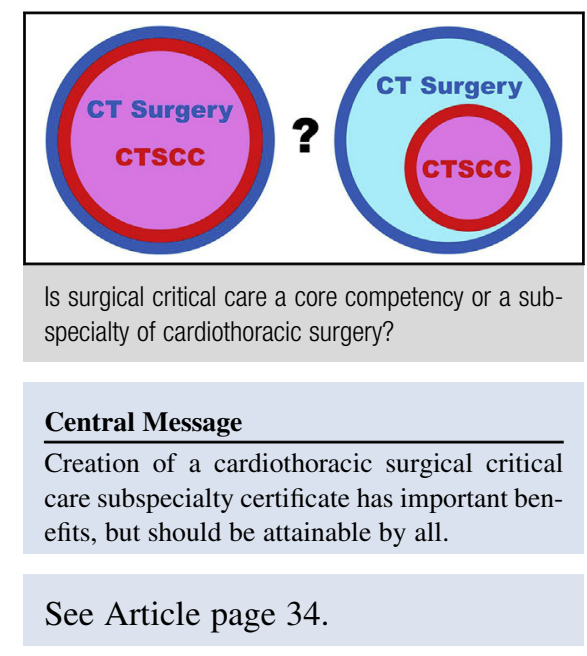

First, several logistical barriers to the approval of the CTSCC subspecialty certificate by the Accreditation Council for Graduate Medical Education (ACGME) and American Board of Medical Specialties are anticipated, owing primarily to the lack of existing critical carecertified thoracic surgeons available to serve as residency program directors. ${ }^{4}$ Second, the precise curriculum and pathway to certification remain somewhat elusive. To date, only a single subspecialty-congenital cardiac surgery-has received a separate certification from the ABTS. Completion of the congenital cardiac surgery subspecialty certificate requires completion of a dedicated 12-month ACGME-approved training program with a defined curriculum and case requirement, as well as passing grades on written and oral subspecialty board examinations. Both Dr Sherif and Dr Katz have asserted that CTSCC subspecialty certification likely would not be as laborious as this, and could entail multiple pathways to certification, including continuing medical education courses and examinations for surgeons currently in practice. ${ }^{1,3}$ Current and future cardiothoracic trainees presumably could obtain CTSCC subspecialty certification within the framework of existing residency training paradigms without the need for additional dedicated training time. The substantive details of these certification pathways have yet to be fully defined or agreed upon, however. Finally, given the ABTS's position that critical care is a core competency of cardiothoracic surgery, there remains a concern that the development of a separate CTSCC subspecialty certificate could potentially undermine the critical care credentials of non-CTSCC-certified 


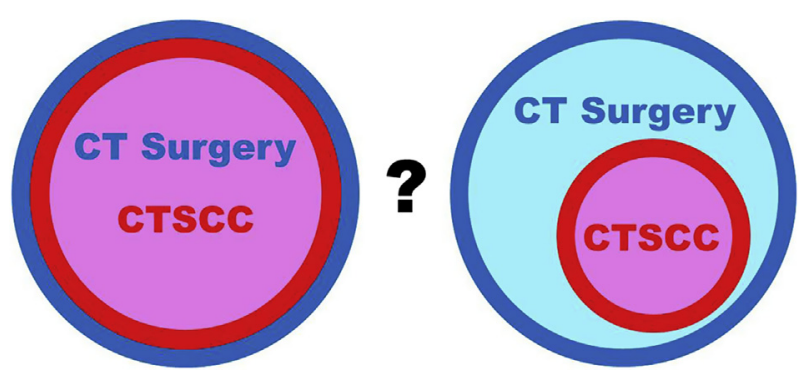

FIGURE 1. Is cardiothoracic surgical critical care (CTSCC) a core competency or a subspecialty of cardiothoracic $(C T)$ surgery?

cardiothoracic surgeons. Once implemented, would some hospitals grant CTICU privileges only to CTSCC-certified surgeons? If so, then most practicing cardiothoracic surgeons would need to seek CTSCC certification to maintain existing CTICU privileges, and these surgeons may view the subspecialty certificate as an unwelcome mandatory regulatory burden. Ideally, the added credentials and critical care expertise provided by the CTSCC subspecialty certificate would be carefully worded to avoid this dichotomy and not detract from the existing critical care credentials currently afforded to all ABTS diplomates.

The importance of cardiothoracic surgeon involvement in the critical care of our patients and the leadership of CTICU teams is indisputable, and creation of a CTSCC subspecialty certificate as outlined by Dr Sherif would unquestionably promote and strengthen these important missions. However, an inclusive CTSCC subspecialty certificate that is attainable by all present and future cardiothoracic surgeons without undue burden is recommended to allow all cardiothoracic surgeons to continue to be recognized and credentialed as specialized critical care physicians.

\section{References}

1. Sherif HM. Cardiothoracic surgical critical care certification: a future of distinction. J Thorac Cardiovasc Surg. 2016;152:34-6.

2. Katz NM. It is time for certification in cardiothoracic critical care? J Thorac Cardiovasc Surg. 2013;145:1446-7.

3. Katz NM. Meeting the expanded challenges of the cardiothoracic intensive care unit. J Thorac Cardiovasc Surg. 2015;150:777-8.

4. Baumgartner WA, Calhoon JH, Shemin RJ, Allen MS. Critical care: American Board of Thoracic Surgery update. J Thorac Cardiovasc Surg. 2013; 145:1448-9. 